Ontologia negativa em psicanálise:

entre ética e epistemologia

Christian Ingo Lenz Dunker

Professor do Instituto de Psicologia da Universidade de São Paulo (USP) e do Mestrado em Psicologia da Unimarco 


\section{Ontologia negativa em psicanálise: entre ética e epistemologia}

O objetivo deste artigo é explorar algumas relações teóricas e clínicas decorrentes das concepções de real e realidade na obra de Lacan. O argumento central é de que a disparidade entre estas duas noções se desdobra em uma importante tensão, a ser mantida, entre ética e epistemologia, no quadro da apreensão filosófica do tratamento psicanalítico. Salienta-se como a perspectiva assumida pelo programa de uma ontologia negativa permite traçar uma linha de diálogo entre diversos projetos clínico teóricos da psicanálise contemporânea, bem como situar alguns marcos significativos na relação entre psicanálise e filosofia. O artigo levanta ainda duas questões que surgem como significativas para os desdobramentos de uma ontologia do negativo em psicanálise: (1) a sua relação com o paradigma da subjetividade melancólica, que caracteriza o surgimento histórico da psicanálise na modernidade; e (2) a sua relação com os traços distintivos que marcam o pensamento sobre o real nas filosofias do século XX.

Palavras-chave: psicanálise, filosofia, ontologia, clínica

\section{Negative ontology in psychoanalysis: between ethics and epistemology} This paper deals with the relationships between theoretical and clinic instances deriving from Lacan's conception of the real and of reality. It's main argument is that the disparity between the latter notions is the spring of the insurmountable tensions between ethics and epistemology, one that a philosophical regard shows to be constitutive of the psychoanalytical practice. Lacan's program of a negative ontology allows us to establish connections between different trends in psychoanalytical thought and practice as well as in general between psychoanalysis and philosophy.

Key words: psychoanalysis, philosophy, ontology, clinic

\section{Por que separar o real da realidade?}

Na obra de Freud é possível separar, com razoável precisão, os momentos de teorização metapsicológica dos momentos de teorização clínica. O mesmo não se dá em Lacan. Suas considerações sobre o método de tratamento e suas ilustrações clínicas combinam-se ao longo da obra com uma seqüência de debates e incorporações cruzadas da metapsicologia com a ciência, a filosofia e a arte. Efeito desse cruzamento é o que poderíamos chamar de migração clínica de conceitos. Ou seja, noções tradicionalmente ligadas à teoria do conhecimento são gradualmente trazidas para a prática clínica, assumindo, finalmente, um determinado valor ético, a partir do qual se desdobram em procedimentos clínicos. Por exemplo, em alguns momentos de sua obra Lacan pretende apresentar de forma sintética o trajeto da cura analítica. É o caso de Além do princípio de realidade (1936), onde encontramos a seguinte passagem:

Sua ação terapêutica [do psicanalista], ao contrário, deve ser essencialmente definida como um duplo movimento pelo qual a imagem, a princípio difusa e fragmentada, é regressivamente assimilada ao real, para ser progressivamente desassimilada do real (interpretação?), isto é restaurada em sua realidade própria. Ação que testemunha a eficiência dessa realidade. (Lacan 19, p. 89)

O trajeto de assimilação regressiva ao real pode ser compreendido como intrínseco ao movimento da transferência. Reforça essa idéia a proximidade estabelecida por Freud entre a transferência e a noção 
de atualização, como um dos sucedâneos da repetição (Freud 13). Esta não parece ser uma tese concernente aos primeiros momentos do ensino de Lacan, pois ela reaparece em 1964, no contexto de um esforço definicional em torno da transferência, que é concebida então como "a atualização da realidade inconsciente" (Lacan, 1964, p.139).

No segundo momento, encontramos o trabalho de desassimilação progressiva do real. Aqui parece tratar-se do esforço empreendido pela interpretação que se apóia na desassimilação ou na separação pela qual se extrai um saber sobre o equívoco da transferência.

O terceiro momento do tratamento psicanalítico é representado, na citação acima, por uma restauração da realidade própria da imagem, ou seja, o momento em que essa realidade é reconhecida como simbólica, dotada então de uma certa eficiência. Salientemos que tal desdobramento da noção de realidade encontra-se já em Freud, tanto como um operador metapsicológico, que permite distinguir entre a realidade psíquica e a realidade histórica (Freud 15), quanto como operador clínico:

Os neuróticos se caracterizam, portanto, por colocar a realidade psíquica (psychiche Realität) acima da realidade factual (faktishe Realität), reagindo a pensamentos da mesma forma como pessoas normais regem apenas a realidades (Normalen nur auf Wirklichkeiten). (Freud 13, p. 89)

Salientemos, na passagem, o uso diferencial de três acepções de realidade: a realidade psíquica, aquela que se mostra em ato na transferência, $a$ realidade factual, determinada por consenso ou verificação empírica, e a realidade como efetividade (Wirklichkeit). Entre o segundo e o terceiro tipo há uma diferença importante: eles parecem opor uma realidade pensada a partir de seus modos de representação à realidade pensada a partir de seus modos de produção. A solução mais trivial consiste em absorver a realidade psíquica do primeiro caso, confirmando, assim, um certo idealismo na apreensão do inconsciente.
Entre os comentadores de Lacan, essa solução redundou na tese de que há uma oposição simples e irreversível entre realidade e real. Contudo, poucos atentaram para a natureza não simétrica dessa oposição:

É assim que nós podemos conhecer os fenômenos, mas o ser permanece incognoscível. A tese de Lacan é outra coisa. Certamente Lacan opõe a realidade ao real. [...] o real é estranho à questão do conhecimento, tanto negativamente (não se o conhece), quanto positivamente (ele não é também incognoscível). (Badiou 1, p. 67)

A realidade seria um conceito fraco, de extração epistemológica, signo do intuitivo e do diverso sensível. Toda a sua complexidade e importância presente no texto de Freud (Freud 14) seria, assim, transferida para o conceito de real. Esse esvaziamento da noção de realidade, sua dissociação em relação à noção de real, trai, como pretendemos mostrar, o núcleo mais original da reflexão lacaniana sobre a questão. Ao identificar a realidade com o universo dos fenômenos (a encarnação da estrutura) e o real com a própria estrutura, acaba-se por transformar o pensamento de Lacan em uma espécie de kantismo sem liberdade, ou por hipertrofiá-lo em um estruturalismo ontológico; como afirmou Deleuze, "um real sem atual, um ideal sem abstrato", puro reservatório capaz de engendrar pelo jogo de suas posições e lugares a diferenciação, a seriação e a causação (Deleuze 7, p. 269). Nessa leitura, a realidade psíquica singular é apenas uma atualização do real da estrutura.

Ocorre que a realidade psíquica, se a apreendemos no quadro das transformações propostas por Lacan, examinadas anteriormente, inclui esse traço de realidade efetiva, ou seja, de atualidade. Atualidade, existência, ou ainda atividade, são formas de concepção do real que primam pela asserção de sua positividade. Contrastam com formas de apreensão do real pela negatividade, o que se costuma associar à 
tradição representacionalista de abordagem do problema e, coextensivamente, a categorias como possibilidade, potência e aparência.

Vê-se, pela asserção de Lacan, que há uma espécie de cruzamento entre as duas séries em sua definição de real. É um argumento central deste artigo que o real em Lacan é abordado intensionalmente pelas vias da negatividade e, no entanto, aproxima-se extensionalmente da realidade como produção de efetividade. Nosso intuito será o de mostrar como esse problema é, simultaneamente, uma questão de interesse filosófico e de relevância clínica. Nosso argumento começa pela idéia de que a noção de realidade esteve no centro das cogitações clínicas de Lacan do início ao fim de seu ensino; ele termina por dizer de que a noção de realidade produz uma espécie de encruzilhada entre ética e epistemologia, cuja solução será mimetizada pela categoria de real.

\section{Da etificação de categorias epistemológicas}

Na conferência Simbólico, imaginário e real (Lacan 21) encontramos novamente a noção de realidade como ponto de orientação terminal para o tratamento. Aqui Lacan discrimina onze momentos do tratamento psicanalítico, pela combinatória entre as categorias de real, simbólico e imaginário, tomadas duas a duas, e divididas entre ações (simbolizar, imaginarizar e realizar) e ordens (o simbólico, o imaginário e o real). O projeto genérico parece ser o de refazer a Fenomenologia do espírito (Hegel 17) na chave da experiência psicanalítica. O momento conclusivo do tratamento, que retoma a estrutura de seu momento inaugural, é assim apresentado como equivalente da realização do simbólico:

sR [realização do simbólico]: que é, em suma, a finalidade de toda e qualquer saúde, que não é (como se crê) adaptar-se a um real mais ou menos bem definido, ou bem organizado, mas fazer reconhecer sua própria realidade; em outras palavras, seu próprio desejo. (Lacan 21 p. 104)
Note-se, nessa passagem, como as referências ao real e à realidade parecem invertidas. O real é sinônimo de uma totalidade organizada e definível ao qual o sujeito não deve ser colocado em relação de adaptação. A realidade aparece ligada ao campo do reconhecimento e ao desejo. Mais do que a tensão entre ideologia e crítica, devemos atentar para a distinção entre uma atividade (a simbolização) e o campo sobre o qual recai ou que se produz nessa atividade (o real). Há aqui um protocolo de subjetivação, aludido pela expressão reconhecer sua própria realidade. Ou seja, não é o real como expressão da identidade (idem), mas como expressão da propriedade (proper), que está em questão. Nessa medida, não haveria lugar para o Um, no sentido da totalidade do Ser, mas apenas para o um, como operatividade ordenadora no contexto da estrutura subjetiva. A unidade ontológica opõe-se assim à efetividade lógica da operação de contagem.

Nesse ponto, a doxa lacaniana acabou por reunir à leitura idealista da noção de realidade psíquica um acréscimo relativista. Desconsiderando, na obra de Lacan, a recorrência do tema do universal em sua tensão com o exame da gramática das formas de negação, há uma interpretação corrente de que o real que interessa à psicanálise não depende nem exige qualquer referência que não a verificada no contexto da transferência.

Afinal, qual a serventia da noção de realidade para a clínica psicanalítica, uma vez que sempre que se trata de final de tratamento vem à tona a noção de realidade ou de real? Isso nos remete a uma virtual teoria da realidade em psicanálise, seu caráter ontológico ou ôntico, e ao problema da natureza das causas que definem tal realidade. Antes que um enfrentamento direto desse problema, o que se observa na teorização clínica de Lacan é que o par de termos real-realidade aparece associado a uma seqüência de noções congêneres de natureza epistemológica: saber, verdade, conhecimento, desconhecimento.

Porém, tais noções, uma vez trazidas para a clínica, rapidamente perdem sua dimensão ligada ao conhecimento e assumem uma di- 
mensão ética. O saber, por exemplo, não está a serviço do conhecimento, apreensão ou representação da realidade, mas da relação intersubjetiva. Por exemplo, o conceito de "sujeito suposto saber", que define a concepção lacaniana de transferência, é utilizado por Lacan em aberta referência à sua extração metafísica aristotélica (Lacan 24). O termo sujeito (hypokeimenon) alude alternativamente ao substrato (suposto), aquilo que permanece na transformação, e ao termo lógico sobre o qual se pode atribuir predicados (saber) mas nunca tomado como um predicado (sujeito). Ou seja, a expressão sujeito suposto saber, virtualmente, é uma tradução que põe em seqüência os sentidos do termo hypokeimenon. Como assinalou Porchat Pereira (30, p. 285) tal termo possui uso ambíguo em Aristóteles, pois designa tanto ser em sentido absoluto quanto ser algo. Ocorre que em Aristóteles essa noção possui a importante função de conectar uma teoria sobre a substância a uma determinada concepção de conhecimento. O sujeito suposto saber lacaniano, ao contrário, é uma noção totalmente inútil do ponto de vista epistemológico. Ele define um modo de relação ético, uma certa experiência amorosa, de desconhecimento ou alienação, mas também um modo de produção da realidade, que ultrapassa inclusive as formas ou objetos nos quais tal realidade pode ser reconhecida, simbolizada ou elaborada pelo sujeito. Ou seja, mantém-se a questão do substrato, elimina-se sua função epistemológica e se a substitui por uma atividade ética. É nesse sentido que a transferência é afirmada como conceito pragmático: "Esse pragmatismo é justificado. É que esse manejo da transferência é idêntico à noção dela, e por menos elaborada que seja esta na prática, ela só pode se incluir nas parcialidades da teoria"(Lacan 22, p. 609)

Em outras palavras, a transferência faz equivaler seu conceito à própria ação que a constitui como tal. $\mathrm{Ou}$, ainda, a concepção que se tenha da transferência, por mais falsa ou equivocada que seja, faz parte do próprio fenômeno da transferência, chamemo-la por este nome ou não. Assim, ela inclui uma espécie de ilusão epis- temológica (sujeito suposto saber) e a própria realidade que esta traz consigo, mas ela não é em si mesma cognoscível nem incognoscível. Disso resulta a dificuldade de sua integração teórica.

\section{Um mapa da psicanálise}

A afinidade entre o tema da realidade e o projeto clínico envolvido no tratamento psicanalítico reaparecerá na obra de Lacan no artigo "Da psicanálise e suas relações com a realidade" (24). Por que Lacan teria empregado a palavra realidade nesse momento de sua obra, em que a noção de real aparece tão bem delineada e, supostamente, em oposição simples e direta com a noção de real? A tese do artigo é de que o tratamento envolve uma experiência que se desdobra em uma tripla divisão subjetiva: saber, verdade e gozo. Essa divisão, uma vez realizada, marcaria o final do tratamento.

Quanto à realidade do sujeito, sua imagem de alienação, pressentida pela crítica social, se revela enfim por desenrolar-se entre o sujeito do conhecimento, o falso sujeito do "eu penso", e este resíduo corporal em que penso haver encarnado suficientemente o Dasein para chamá-lo pelo nome que ele deve a mim: ou seja, o objeto $a$. (Lacan 25, p. 357)

Estamos em um momento no qual Lacan está delineando mais claramente sua estratégia com relação ao tema da realidade. Há, por um lado, o falso sujeito, o sujeito do conhecimento; de outro, a questão do objeto e do ser. Sobre esse par aplica-se uma gramática particular da negatividade, uma negação da universalidade que não é proporcional à negação existencial: não sou onde penso, penso onde não sou. Contudo, há uma leitura simplesmente dualista desse resultado, uma leitura pela qual se afirmará simplesmente a incomensurabilidade entre duas "não-substâncias". Desejo e gozo, sujeito e linguagem, saber e verdade são figuras que podem ser absorvidas 
nesse dualismo. Ocorre que é precisamente nesse ponto que Lacan reafirmará seu monismo materialista com o conceito de real. O real não é a contradição ou mistura dessas duas não-substâncias, mas a negatividade que se deduz logicamente da apreensão da realidade. $\mathrm{O}$ real não se opõe nem ao sensível nem ao inteligível, mas os presume.

Essa é a direção sugerida pelo trabalho de Ménard (29), que situa a negatividade como caminho para a saída da ontologia. É pela análise das estratégias de negação da realidade, pela distinção entre formas boas e ruins de negação, pelo exame dos modos próprios e impróprios de exclusão, que o problema da ontologia poderia ser contornado em psicanálise.

A negação não tem relação com o não-ser, ela tem relação com a diferença entre ser excluído e existir. Perguntar-se-á se ainda existe um denominador comum entre a abordagem filosófica da questão do ser, a abordagem lógica da questão da existência e a abordagem psicanalítica do real. (Menard 29, p. 194)

Havendo ou não solidez ou consenso sobre um denominador comum, fato é que se poderia traçar um mapa da psicanálise contemporânea tendo em vista a partilha em torno do problema da realidade e os critérios sugeridos acima. De forma muito breve, e apenas para criar um cenário circunstancial, distingo algumas posições relevantes:

(a) Narrativismo: esta linha de reflexão coloca que a questão da realidade está esgotada para a psicanálise e que podemos prescindir de qualquer referencialismo. Com uma boa concepção pragmática de linguagem é possível dar cabo da tarefa clínica. Um antecendente importante aqui é a crítica de Spence (33) ao predomínio da narrativa investigativa em psicanálise e sua metáfora dominante baseada na lógica da descoberta, em detrimento da lógica da invenção. Notase uma substituição da confiança epistêmica e do realismo ingênuo pelo reconhecimento do caráter metafórico da teoria psicanalítica e do caráter construtivista de sua prática. Freire Costa $(10 ; 11)$, por exemplo, tem se apoiado na concepção pragmática de Wittgenstein e Davidson para sugerir um projeto clínico que abandone os traços essencialistas representacionais e fundacionistas da clínica psicanalítica, buscando, em seu lugar, um entendimento da clínica como atividade de redescrição e reformulação de crenças e desejos. Em uma direção homóloga, mas de outra natureza, os trabalhos de Gabbi Jr. (1994, 1999) têm mostrado a possibilidade de compreender a obra de Freud, mormente em seus momentos seminais, como desnecessariamente ligada à procura de uma referência; também pôe em evidência o caráter prescindível do referencialismo face a sua substituição por uma teoria do sentido ou da racionalidade lingüística, pragmática ou não. Estamos aqui no plano da análise lógico-lingüística (não estrutural) do problema da existência. Observe-se que, para os narrativistas, o problema da realidade em psicanálise é substituído, inteiramente, pelo problema da lógica ou racionalidade interna à produção de sentido.

(b) Refundacionismo: aqui se argumenta que é possível extrair da psicanálise uma verdadeira lógica da descoberta. A realidade à qual esta se endereça pode ser sustentada positivamente, quer na contraprova neurológica, quer em alguma estratégia transcendental de construção de objetos. Argumenta-se aqui que uma boa teoria da mente, seja ela de extração lingüística, social ou biológica, seria suficiente para dar conta não só da legitimidade epistemológica da psicanálise, mas de sua tarefa clínica. Muito mais interessante do que essa estratégia, que na verdade representa uma espécie de refundacionalismo epistemológico, é a tentativa de alguns autores de pensar a psicanálise como a refundação, ou a instalação mesma, de uma experiência. Poderíamos falar, então em uma espécie de refundacionalismo ético. Luís Claudio Figueiredo (8; 9) e Nelson Coelho Jr. (6) têm se dirigido para essa perspectiva, assumindo a fenomenologia de Husserl a Merleau-Ponty como referência. Aqui o problema da realidade é vertido no conceito de experiência e abordado pelas vias 
de uma espécie de ontologia regional, não apenas no sentido do seu fundamento perceptivo, mnêmico ou historial, mas também tendo em vista a regionalidade própria de certas constituições subjetivas, tendo em vista principalmente seu nível pré-reflexivo. Winiccott e em geral os autores da psicanálise que orientam-se para a investigação das experiências primitivas da constituição da subjetividade e da objetividade tornam-se aqui referências significativas.

(c) Criticismo: para esta posição, o tema da realidade deve ser abordado pelas vias da negatividade. Isso implica uma certa separação metodológica entre as considerações ontológicas e o plano de apreensão metodológico da realidade a ser considerada em psicanálise. São autores que se dedicam a rever criticamente problemas como o da temporalidade e da ficcionalização, conjugando, principalmente, a experiência clínica (notadamente as noções de construção e sublimação) com a literatura e com o campo genérico da estética. Nelson da Silva Jr. (31) tem trabalhado nessa direção, baseando-se na hermenêutica crítica. Joel Birman $(3 ; 4)$ parece representar outra faceta dessa posição, neste caso com apoio dos estudos de Foucault. No fundo, o criticismo corresponde a uma espécie de deslocamento estratégico do problema da realidade para o problema das condições de possibilidade acerca de sua representação, o que tradicionalmente redunda em uma epistemologização da realidade. Mas se poderia pensar, como parece propor essa posição, que a experiência estética nos forneceria uma espécie de modelo alternativo - um modelo crítico e com base nas formas de negatividade, e não de positividade, na apreensão do real.

(d) Ontologia negativa: neste caso o problema da realidade em psicanálise é mantido em tensionamento com a noção de real. Trata-se de mostrar como os modos de subjetivação na clínica lacaniana são fundamentalmente estruturas de reconhecimento de uma negação ontológica que se manifesta de maneira privilegiada na confrontação entre sujeito e objeto, como postula Safatle (32). Para esta posição, seria preciso recuperar a noção de pulsão no quadro de uma dialéti- ca negativa e fora da lógica de identidade e da substancialização. A referência fundamental aqui é Hegel, mas também Adorno e pensadores pós-lacanianos contemporâneos, como Zizek e Badiou.

O narrativismo nos traz uma importante reflexão sobre a importância do caráter pragmático da linguagem e sobre a historicização dos modos de subjetivação empreendidos pela psicanálise. Sua crítica ao ontologismo baseia-se, contudo, em uma oposição ao ontologismo positivo, reificador e essencialista. O criticismo, por sua vez, considera tal oposição desnecessária, sobretudo porque enfatiza os modos negativos de tratamento do real, constituindo-se o real, todavia, em uma espécie de idéia reguladora ou de conjectura necessária. Em contrapartida, o refundacionalismo, principalmente em sua versão mais elaborada, procura uma solução integradora pela via de uma acepção de real que possa ser deduzida dos fracassos dos modos de representação e subjetivação. Há, portanto, uma divisão entre aqueles que aceitam a necessidade ética de uma teoria psicanalítica do real (refundacionalismo e criticismo) e aqueles que a consideram inútil e perigosa (narrativismo). Por outro lado, há uma divisão entre aqueles que aceitam a primazia da negatividade em termos epistemológicos (narrativismo e criticismo) e aqueles que a refutam (refundacionalismo).

A ontologia negativa poderia situar-se, assim, como uma espécie de síntese disjuntiva (para usar a expressão sugerida por Ménard) entre o realismo ético e a epistemologia da negatividade. Síntese disjuntiva designa aqui não a reunião dessa tensão numa integração resolutiva, mas uma concepção baseada no caráter irredutível e necessário dessa tensão. Daí suas duas noções-chaves o real e o ato. Trata-se, em outras palavras, de uma teoria sobre a impossibilidade de epistemologização da ética e uma teoria sobre a impossibilidade de etificação da epistemologia. Talvez a ontologia negativa não seja uma posição independente das demais, mas apenas uma tentativa de elaborar suas diferenças, tendo assim um papel decisivo para manter o potencial crítico e renovador que se espera da partilha sobre a noção de realidade. 
Voltemos ao nosso problema: como uma ontologia baseada exclusivamente na negatividade pode servir aos propósitos de uma orientação clínica do sujeito que não se dilua no reconhecimento de uma heteronomia radical, cujo potencial ideológico não se pode deixar de pôr em questão. Em outras palavras, se consideramos o percurso de um tratamento analítico como um progresso de desencantamento de ideais, de elaboração do luto fundamental e de reconhecimento da falta constitutiva - em todas as figuras que a castração pode assumir -, como distinguir esse processo da mera absorção de uma teologia negativa, ou de uma ética da resignação infinita, como sugeriu Deleuze?

A questão pode ser enunciada em um formato criticista, para lembrar o trabalho de Silva Júnior (31): a libertação de si e a abertura para um passado imprevisível são suficientes para nos livrar de um niilismo depressivo? Seriam o apelo à sublimação e à construção, como estratégias para a ficcionalização de si, suficentes para nos distanciar da ética da renúncia?

Ou ainda, na chave da pesquisa de Safatle (32): será que a destituição subjetiva e a travessia do fantasma, critérios lacanianos do final do tratamento, pensadas no quadro de uma ontologia negativa, não nos levariam a um saldo cínico irremediável, uma espécie de perversão adaptada, cujo principal traço seria a apatia?

Nestas versões do problema, há uma espécie de pressentimento de que uma adesão extensiva ao real como pura negatividade não precisa, necessariamente, nos conduzir a uma eticidade baseada apenas em critérios negativos na relação do sujeito com a verdade, como quer o narrativismo.

O realismo epistemológico não comporta a mesma espessura teórica e clínica do realismo ético. Reenunciemos nossa questão: a psicanálise seria de fato uma atividade orientada apenas pela via de levare, cujo horizonte é a reconciliação entre o ser e o dever ser, ou será que ela nos promete algo também na via de pore, cujo horizonte é a criação de algo entre o ser e o poder ser, como parecem sugerir Figueiredo
(9) e Birman (4). Nessa medida, o narrativismo e o criticismo estão preocupados em valorizar, na psicanálise, a lógica da invenção, enquanto refundacionalismo e a ontologia negativa preocupam-se em manter, dentro de certos limites, a lógica da descoberta.

Veja-se que o que está em questão novamente é o caráter adaptacionista da psicanálise, não mais como nos apontava a crítica de Lacan à psicanálise da década de 1950, baseada na adaptação do eu à realidade, mas uma adaptação "negativa", baseada na "aceitação" da comensurabilidade da verdade da falta com a negatividade do real.

\section{Impasses da negatividade: a subjetividade melancólica}

Habermas (16) tem chamado nossa atenção para Hegel como um autor-chave no processo de destranscendentalização do sujeito moderno. O principal argumento para essa interpretação reside na introdução da linguagem, do trabalho e das relações de reconhecimento como categorias críticas ao mentalismo kantiano e também como meios pelos quais o sujeito fixa sua relação com o mundo e com os outros. A partir de então, a problemática da intersubjetividade não poderá mais ser separada de sua dupla referência: a) a subversão do objeto do conhecimento como categoria epistemológica; b) a subversão do Outro como alteridade ética e mediador universal.

A descoberta da noção de mediação, como estrutura anterior e determinante das relações entre sujeito e objeto, como articulador entre meios e fins, ou ainda como juntura entre o particular e universal, permite a Hegel desidentificar o sujeito cognoscente do Eu. O preço dessa desidentificação é uma relativa dispersão das formas de entendimento da reflexividade no nível do sujeito. Trabalho, linguagem e reconhecimento podem ser lidos, na esfera da constituição do sujeito, tanto em uma chave positiva - o que nos remeterá virtualmente a uma antropologia - quanto em chave negativa - o que nos 
remeterá a uma ontologia. Observe-se que as absorções teóricas que marcam o percurso de Lacan têm sempre a marca deste segundo aspecto: a dialética com ênfase negativa, de Kojéve; a linguagem considerada como sistema de elementos sem positividade própria, em Saussure e Lévy-Strauss; a função axiomática do zero e do conjunto vazio na lógica de Frege; a escrita do não-todo extraída da matemática de Cantor e Gödel. Contudo, é preciso salientar que esse esforço de destranscendentalização do sujeito (pela via do negativo) é acompanhado da reflexão ontológica em torno do objeto (teoria do gozo e da sexualidade, concepção do objeto $a$ etc).

Trabalho, linguagem e reconhecimento: grosso modo, são também estas as tarefas que se poderia esperar de um tratamento psicanalítico: rememoração (nomeação pela linguagem), elaboração (Durcharbeiten, trabalho com o objeto), subjetivação (progressão na dialética do reconhecimento). Tal experiência (Ehrfahrung) se orienta para duas realizações subjetivas:

(1) a constatação de uma certa negatividade, inconsistência ou impossibilidade no nível do Outro.

(2) a redução do potencial de alienação contido em um objeto que suporta a fantasia do sujeito.

Objeto e Outro - são os dois critérios-limite da análise, critérios que procedem de campos originariamente distintos: a reflexão sobre o objeto nasce na epistemologia moderna; a noção de Outro, por sua vez, procede da reflexão ético-política do Ocidente.

Note-se como, ao descobrir o papel epistemológico do trabalho, da linguagem e do reconhecimento, o autor da Fenomenologia do espírito está, simultaneamente, acumulando funções distintas para a noção nascente de Outro. Ou seja, ao ler em chave intersubjetiva a noção aristotélica de particular, Hegel sobrepõe ética e epistemologia no mesmo movimento em que estipula o lugar em que verdade e real devem se reconciliar:
Hegel é o primeiro a correlacionar os três aspectos da lógica tradicional com os três aspectos nos quais os indivíduos socializados se reconhecem reciprocamente: a saber, como pessoas em geral, que se igualam às outras pessoas em aspectos essenciais; como membros particulares de uma comunidade, que compartilham peculiaridades de sua comunidade de origem; e como indivíduos, que se distinguem de todos os demais indivíduos. (Habermas 16, p. 196)

Está aqui a tradução intersubjetiva e ética das noções aristotélicas de genus, species e ens singularis. Está aqui também o projeto que marcará a contradição entre universalismo simbólico e particularismo imaginário. É daí que se precipitará, também historicamente, a idéia de que a única forma de apreensão intersubjetiva do real reside na singularidade - singularidade que se realizaria paradoxalmente com a negativização do próprio sujeito na forma do espírito absoluto.

Esse programa é herdado por Lacan e trazido para a psicanálise. Já em Da psicose paranóica e suas relações com a personalidade (18), Lacan contesta, na concepção freudiana de narcisismo, justamente sua indistinção entre uma acepção epistemológica e uma acepção psicológica de sujeito. Lembremos que a introdução da noção de personalidade teria por finalidade restituir ao sujeito sua incidência ética, indexada em atributos como responsabilidade e realização social de ideais. Portanto, antes mesmo de sua freqüência aos seminários de Kojéve, Lacan parece enredado pelas relações problemáticas entre ética e epistemologia. Isso se explicita em uma primeira concepção ética de desejo que gira em torno de categorias epistemológicas, tais como conhecimento, desconhecimento e reconhecimento. O que essa curiosa combinação tem por efeito é uma articulação possível entre desejo e sujeito que possa dotar ambos de um certo grau de realidade e, ao mesmo tempo, marcar suas vias de relação com o signo da negatividade (a ação negadora do desejo, a palavra como morte da coisa etc) 
No artigo sobre o estádio do espelho (Lacan 20), vemos essa presença singular, negativa e real do sujeito ser indicada da seguinte maneira:

(...) a matriz simbólica em que o Je se precipita numa forma primordial, antes de se objetivar na dialética da identificação como o outro e antes que a linguagem lhe restitua no universal, sua função de sujeito. (Lacan 19 p.97)

Entre o particular de uma forma primordial, dada, digamos, por sua comunidade de origem - por figuras prestativas, segundo Freud (12) -, e o universal abstrato da linguagem, nesta posição intervalar, mas única realmente concebível, ali está o sujeito. Em outras palavras, o sujeito é essa negatividade ontológica, essa beànce; o sujeito em seu retorno contínuo a si e em separação constante de si. Mas, afinal, quando real e racional se reconciliam na experiência psicanalítica? Quando o sujeito será restituído no universal? Ou, ainda, quando o sujeito superará a dialética da identificação com o outro? A pergunta só faz sentido se identificamos, por analogia, o fim da história com o final da análise. Para aqueles que pensam que Hegel é um episódio de juventude em Lacan, basta verificar como o Seminário XVI (Lacan, 1967) chamado, justamente, de um Outro ao outro, mantém, no essencial, a mesma problemática relação entre o objeto e o Outro. Agora, em vez de desconhecimento e reconhecimento, a questão se coloca entre saber e verdade, ou ainda, como quero propor, entre epistemologia e ética.

Fato é que se reconhecemos em Hegel a descoberta da intersubjetividade e se localizamos em Freud a condição de experiência intersubjetiva do inconsciente (negatividade que é real) e a experiência "interobjetiva" das pulsões (real que é negatividade), podemos assinalar uma série de traços dessa experiência: sua separação, perda ou descentramento de si, seu exílio, sua indeterminação, sua forma sem qualidades, seu efeito sem causa, sua liberdade sem autonomia.
Todos esses traços combinam com o que Calligaris (2004) chamou de subjetividade melancólica, subjetividade cuja reconstrução histórica na modernidade nos tem feito reencontrar sempre no núcleo do sujeito essa experiência de perda e seu luto incurável. Seria este o único real ao qual o sujeito considerado pela psicanálise deveria admitir e se conformar? É esta a verdade final do desejo ao qual a ética trágica da psicanálise viria a recompor, unindo o que é ao que deve ser? Será preciso demonstrar que a ontologia negativa, que aqui apresentamos, pode dar conta dessa objeção.

\section{A paixão pelo real e seus desatinos}

O paradigma da subjetividade melancólica não está presente apenas na psicanálise, muito menos na psicanálise de extração lacaniana. Várias das afinidades entre psicanálise e marxismo - que nunca se sabe bem como combinar - e também das homologias entre a psicanálise e a ontologia heideggeriana, ou ainda das congruências entre psicanálise e teoria crítica, podem ser atribuídas a essa partilha entre o real, a negatividade e o sujeito. Como afirmou Olgária Matos ,ao lembrar as origens pascalianas da razão crítica,

(...) o espanto metafísico do homem frente ao espetáculo de um mundo aberto e sem limite no tempo e no espaço, e, sobretudo, de um mundo privado de centro e de sentido, no qual o destino é tão somente errância e o homem, alguém que perdeu seu lugar, seu lar. Não há mais neste mundo ponto fixo, mas apenas pontos de vista. (Matos 28, p. 324)

Se o destino é somente errância e se não há mais lugar para o sujeito em sua própria morada (ou na morada do Outro), a única forma possível de real estará marcada pela negatividade, pela renúncia, pelo assujeitamento. Mas essa subjetividade, na qual a sombra do 
objeto caiu sobre o sujeito, deve antes ser caracterizada como uma resposta do que como uma pergunta. A pergunta que lhe cabe é uma pergunta apenas e tão somente concebível em termos éticos, uma pergunta cuja enunciação é uma paixão: a paixão pelo real.

Sem procurar fazer aqui uma reconstrução do percurso dessa paixão, que de certa forma corresponderia ao próprio trabalho crítico de exame, arqueologia ou desconstrução das condições de possibilidade dos modos de subjetivação da modernidade, podemos dizer, com Badiou (2), que trata-se de uma paixão a quatro termos aparentemente inconciliáveis. Primeiro, é a paixão impossível pela revolta e insubmissão ao destino, paixão delirante de autonomia, como aponta Lacan na abertura do seminário sobre a ética da psicanálise (Lacan 23). Em segundo lugar, é uma paixão pela coerência, expressa pelo desejo de justificação e conciliação entre memória e história; desejo de incorporação de uma experiência de fragmentação, acaso e ambigüidade. Terceiro, como toda paixão, a paixão pelo real aspira a sua universalização, procura desesperadamente superar o particular do qual ela depende e encontrar o equivalente geral de sua experiência. Finalmente, e este é o quarto traço diagnóstico desta paixão pelo real, trata-se de uma esperança na aposta, de um gosto pelo acaso e pela contingência, que essa paixão moderna tende a enfrentar pelas exigências de fidelidade a um evento.

Ocorre que essa paixão pelo real acaba por criar seu próprio descontentamento com a verdade que lhe cabe. Nerval dizia que o melancólico vê as coisas como elas realmente são. Esse desejo de ver as coisas como elas realmente são está na raiz de inúmeras ambições clínicas da psicanálise. Isso explica como as noções de verdade, saber, realidade e, no conjunto, a questão do real, gradualmente são incorporadas como categorias clínicas. Esse processo já está agudamente presente no último Freud, para quem a própria neurose se define, cada vez mais, como um duplo processo de fuga da realidade e de fuga para a realidade. Em ambos os casos, a neurose incide como uma verdadeira alienação da realidade, tanto no sentido de "não se reconhecer em" (realidade psíquica) quanto no sentido de "negar a" (realidade operativa - Wirklichkeit). Ocorre, então, que a neurose define-se cada vez mais em relação à noção de realidade.

Note-se que tal conclusão não é nem exclusiva nem original em Lacan; já a psicanálise do eu, com uma versão sociológica de realidade, Winnicott, com uma revisão própria da "realidade da ilusão", e Klein, com sua teoria da "realidade das relações de objeto" (interna e externa), conduziram-se, teoricamente, de maneira semelhante. No fundo são todas elas concepções que giram em torno da realidade precária do objeto. Isso levou, durante algum tempo, ao descaminho de imaginar que, no fundo, o que se deveria esperar da metapsicologia era uma espécie de teoria do conhecimento psicanaliticamente orientada, responsiva aos critérios de coerência e universalidade mas refratária aos critérios formais da aposta e da revolta.

No mesmo período vimos também a proliferação do equívoco inverso, qual seja, o de imaginar que a produção de uma "experiência verdadeira", no sentido de autêntica, sincera, engajada e reparadora, poderia nos dar o norte ético da ação do analista. Neste caso, é a noção etificada de verdade que se impõe à de realidade. Assim se satisfazem as exigências de aposta e revolta, presentes na paixão pelo real, mas ao preço de um relativismo ético, de um irracionalismo teórico e do desconhecimento da realidade própria no nível do Outro. Aqui, as exigências conceituais de universalidade e coerência ficam de fora.

Meu argumento é que, no fundo, para manter a paixão pelo real sem responder a ela apenas com uma ética da renúncia, implicando instalação irrefletida no quadro da subjetividade melancólica, é preciso manter em relação de negatividade mútua a vertente ética e a vertente epistemológica na consideração da própria ontologia para a psicanálise. Clinicamente, isso se traduz pela síntese disjuntiva entre dois projetos clínicos: (1) a demonstração da falta ou inconsistência no nível do Outro; e (2) a experiência com o objeto "sensível de um além do princípio de realidade", próprio da travessia do fantasma (Lacan 24, p. 356). 
Neste ponto, há um retorno deslocado da "integração" hegeliana. O Outro como meio universal, ordem simbólica - com ou sem face - parece se desconectar do objeto (sistema simbólico e semblante real) do qual ele supostamente seria uma decorrência. A relação do sujeito com os objetos não é simétrica nem proporcional à relação do outro com o sujeito. Estamos aqui no núcleo problemático das relações entre a matriz epistemológica e a ética de teorização da clínica psicanalítica.

Como vimos, o amplo espectro de projetos clínicos em psicanálise poderia se dividir entre uma tendência epistemologizante e outra de perfil etificador. O mais comum é que encontremos formas combinadas e tentativas de resolver, na especificidade do âmbito clínico, exigências sentidas como antagônicas no interior da paixão pelo real e sua resposta histórica: a subjetividade melancólica.

\section{Conclusão}

Partimos de uma problematização acerca da oposição simples entre as noções de realidade e real em Lacan. Vimos que essa oposição deveria ser tomada de maneira mais complexa, de modo a incluir uma distinção inicial entre a noção epistemológica e, no entanto, clínica, de realidade, e a noção não epistemológica de real. Vimos em seguida que a noção de transferência representa uma verdadeira objeção à captura do outro como objeto de conhecimento, e uma conseqüente instabilidade na noção de realidade assim presumida.

Defendemos que o posicionamento diante do problema da realidade em psicanálise é útil tanto para dirimir diferenças em termos de projetos clínicos como para firmar uma rede de relações possíveis entre psicanálise e filosofia. Tais relações passam tanto pela assimilação de uma concepção sobre o ser quanto pela abordagem lógicolingüística da existência. É no quadro dessa relação que se pode julgar a procedência e relevância de uma ontologia para a psicanálise.
De fato, tendo em vista tal problema, pudemos reler diferentes projetos clínicos teóricos da psicanálise contemporânea e também localizar algumas de suas questões estratégicas. Defendemos, neste contexto, a possibilidade e relevância de uma ontologia em psicanálise, apoiados principalmente no trabalho de Safatle (32). Entendemos que tal perspectiva pode oferecer uma alternativa crítica para as formas canônicas de leitura de Lacan, que postulam quer uma espécie de kantismo lacaniano (que toma a linguagem por transcendental), quer uma ontologia da estrutura ou do gozo. Além disso, tal perspectiva sugere um diálogo mais próximo com outros projetos teóricos na psicanálise contemporânea, não apenas de extração lacaniana.

Argumentamos que um ponto central no projeto de uma ontologia negativa da psicanálise é a síntese disjuntiva entre a vertente epistêmica e a vertente ética de consideração do tratamento e da teorização psicanalítica. Sugerimos que Hegel tem um papel importante nessa tarefa.

Em seguida, abordamos duas objeções que se poderia levantar contra tal posição: (1) a imersão da ontologia negativa em uma espécie de teologia negativa, cujo produto histórico correspondente seria a subjetividade melancólica; (2) a dificuldade em apreender todas as exigências históricas colocadas pela noção de real, em termos dos modos de subjetivação que lhe seriam correspondentes.

\section{Referências bibliográficas}

1. BADIOU, Alain "Lacan e o real". In Garcia, Célio (org.). Conferências de Alain Badiou no Brasil. Belo Horizonte: autêntica. 1999.

2. —_ "Situação da filosofia no mundo contemporâneo". In Para uma Nova teoria do sujeito. Rio de Janeiro: Relume-Dumará, 1994.

3. BIRMAN, Joel. - Por uma estilística da existência. São Paulo: 34, 1996.

4. __ Estilo e modernidade em psicanálise, São Paulo: 34, 1997. 
5. CALLIGARIS, Contardo. Comunicação oral no Centro de Estudos Psicanalíticos. São Paulo, 2004.

6. COELHO JR. Nelson; Figueiredo, Luís Claudio - Ética e técnica em psicanálise, São Paulo: Escuta, 2000.

7. DELEUZE, Gilles. "Como reconhecer o estruturalismo". In Chatelet, F. (org) História da Filosofia Vol. IV: o século XX.. Lisboa: Dom Quixote, 1995.

8. FIGUEIREDO, Luís Cláudio. Escutar, recordar, dizer - encontros heideggerianos com a clínica psicanalítica. São Paulo: Escuta/Educ, 1994.

9. —_Ementos para a clínica contemporânea, São Paulo: Escuta, 2003.

10. FREIRE COSTA, Jurandir. "Pragmática e processo analítico: Freud, Wittgenstein, Davidson, Rorty”. In Redescrições da psicanálise. Rio de Janeiro: RelumeDumará, 1994.

11. — A face e o verso. São Paulo: Escuta, 1995.

12. FREUD, Sigmund. "Projeto de psicologia científica para neurólogos (1895)". In Sigmund Freud Obras Completas V. I. Buenos Aires: Amorrortu, 1988

13. _ “Recordar, repetir, elaborar (1914g)". In Sigmund Freud Obras Completas V. XII. Buenos Aires: Amorrortu, 1988.

14. __ “A perda da realidade na neurose e na psicose (1924 a)". In Sigmund Freud Obras Completas V. XIX. Buenos Aires: Amorrortu, 1988.

15. __ “Moisés y la religión monoteísta (1939a)”. In Sigmund Freud Obras Completas V. XXIII. Buenos Aires: Amorrortu, 1988.

16. HABERMAS, Jürgen. Verdade e justificação. São Paulo: Loyola, 2004

17. HEGEL, Georg. W. F. Fenomenologia do espirito. Petrópolis: Vozes, 1992

18. LACAN, Jacques. Da psicose paranóica e suas relações com a personalidade (1932). Rio de Janeiro: Forense, 1988.

19. —_ “Além do princípio de realidade (1936)". In Escritos. Rio de Janeiro: Jorge Zahar, 2000.

20. — "O estádio do espelho como formador da função do eu tal como nos é revelado na experiência psicanalítica”. In Escritos. Rio de Janeiro: Jorge Zahar, 1998.

21. —— “S.I.R" (1953). In Cadernos Lacan - Parte 1. Porto Alegre: Associação Psicanalítica de Porto Alegre, s.d.

22. —_ "Direção do tratamento e os princípios de seu poder (1958)". In Escritos. Rio de Janeiro: Jorge Zahar, 1998.
23. LACAN, Jacques. O Seminário, livro VI: A Ética da Psicanálise, Rio de Janeiro: Jorge Zahar, 1987.

24. — “Da psicanálise em suas relações com a realidade (1967)". In Outros escritos. Rio de Janeiro: Jorge Zahar, 2003.

25. —_ "Proposição de 9 de outubro de 1967 sobre o psicanalista de escola (1967)". In Outros escritos, Rio de Janeiro: Jorge Zahar, 2003.

26. - O Seminário, livro XVI: de um Outro ao outro (inédito).

27. — O Seminário, livro XI: Os quatro conceitos fundamentais da psicanálise. Rio de Janeiro: Jorge Zahar, 1988.

28. MATOS, Olgária C. F. - Os arcanos do inteiramente outro - a escola de Frankfurt, a melancolia e a revolução. São Paulo: Brasiliense, 1989.

29. MENARD, Monique D. "A negação como saída da ontologia”. In Iannini, G. et al (org), O tempo, o objeto e o avesso. Belo Horizonte: Autêntica, 2004

30. PORCHAT PEREIRA, Oswaldo. Ciência e dialética em Aristóteles. São Paulo: Unesp, 2000.

31. SILVA, Jr, Nelson.Modelos de subjetividade em Fernando Pessoa e Freud. Da catarse à abertura de um passado imprevisível. Campinas: Mercado das Letras, 1998.

32. SAFATLE, Vladimir. A paixão do negativo - modos de subjetivação e dialética na psicanálise lacaniana (no prelo).

33. SPENCE, Donald P. A metáfora freudiana - para uma mudança paradigmática da psicanálise. Rio de Janeiro: Imago, 1992. 